\title{
QUEEN'S
UNIVERSITY
BELFAST
}

\section{Paternalism and Populations}

Walker, T. (2016). Paternalism and Populations. Public Health Ethics, 9(1), 46-54.

https://doi.org/10.1093/phe/phv019

Published in:

Public Health Ethics

Document Version:

Peer reviewed version

Queen's University Belfast - Research Portal:

Link to publication record in Queen's University Belfast Research Portal

Publisher rights

(C) 2015 Oxford University Press

Apply 24 month embargo from online publication.

This is a pre-copyedited, author-produced PDF of an article accepted for publication in Public Health Ethics following peer review. The version of record, Walker, T 2015, 'Paternalism and Populations' Public Health Ethics DOI: 10.1093/phe/phv019, is available online at: http://phe. oxfordjournals. org/content/early/2015/07/15/phe.phv019.abstract?sid=17a01eea-1afb-468f-af6c-d53ec153c65e

\section{General rights}

Copyright for the publications made accessible via the Queen's University Belfast Research Portal is retained by the author(s) and / or other copyright owners and it is a condition of accessing these publications that users recognise and abide by the legal requirements associated with these rights.

\section{Take down policy}

The Research Portal is Queen's institutional repository that provides access to Queen's research output. Every effort has been made to ensure that content in the Research Portal does not infringe any person's rights, or applicable UK laws. If you discover content in the Research Portal that you believe breaches copyright or violates any law, please contact openaccess@qub.ac.uk. 


\section{PATERNALISM AND POPULATIONS}

\section{$\underline{\text { Introduction }}$}

It appears to be uncontroversial that some public health policies are paternalistic. Indeed policies that make it mandatory to wear seatbelts or motorbike helmets are often the first things writers reach for when looking for an example of paternalism (see Dworkin, 2011, p.336; Coons and Weber, 2013, p.1). It is a feature of such policies that they target groups of people. In contrast, accounts of what paternalism is standardly define it in such a way that the target of paternalism is an individual (see, for example, Feinberg, 1986, pp.4-5; Dworkin, 1988, p.123; Archard, 1990, p.36; Beauchamp and Childress, 2009, p.208; Dworkin, 2010; Dworkin, 2011, pp.361-2). In this paper I will argue that this creates a problem both for these accounts of what paternalism is, and for the view that because such policies are paternalistic they are at least pro tanto morally wrong. ${ }^{1}$

Before beginning it is worth explaining why this is important given that James Wilson has recently argued that it is mistake to frame discussions of public health policies in terms of paternalism because there are significant difficulties in determining whether a policy is paternalistic (Wilson, 2011). Wilson argues that to be paternalistic a policy must have a certain aim (benefitting those whose liberty is infringed by it) but that in practice policies are often introduced with more than one aim. There are various ways in which we might define paternalism to take account of this: for example, that a policy is paternalistic if at least one of its aims is paternalistic, or that it is paternalistic if its only aim is 
paternalistic. However, Wilson argues that neither of these options will work and also that determining some position between them is hard to justify (Wilson, 2011, p.272). This leaves it unclear whether any actual policies can be said to be paternalistic.

Wilson's argument here appears to move too quickly. It does not seem unreasonable to hold that a policy is paternalistic if it is introduced with the sole aim of benefitting those whose freedom it infringes. Wilson argues that if this were the case then in practice "no policy would be found to be paternalistic, as there will always be a possible non-paternalistic justification or motivation for policies which have a large paternalistic commitment." (Wilson, 2011, p.271) However, it is unclear why the mere possibility that a policy could have been motived on other grounds is a problem. On the account I will be advocating what matters is the actual aim of those who introduced the policy - that they could have introduced it with a different aim is to that extent irrelevant. Furthermore, in practice there will be cases where there are reasonable grounds to think that a policy is being introduced with the sole aim of benefitting those whose freedom is infringed by it: for example, those introducing the policy may explicitly state that this is their sole aim, or the policy may be introduced with only a single target (such as reducing deaths from vehicle collisions by $\mathrm{x} \%$ ) to assess whether it has met its aim. Whilst these do not provide conclusive evidence that a policy has been introduced with only one aim it would not be unreasonable for an opponent to argue that he has good reason to think that it does. 
A second reason for addressing this topic despite Wilson's argument is strategic. I am broadly sympathetic to his idea that in trying to determine whether to adopt a policy we should focus on whether the infringement in liberty is justified, rather than on whether the policy is paternalistic or not. However, in practice opponents of public health policies sometimes object to them on the grounds that they are paternalistic (and I have argued that at least in some cases it may be reasonable for them to do so). To respond by arguing that the infringement is justified would be to talk past them and not really address their objection at all. As such, in this paper I will start from a position that accepts that the kinds of policy I am concerned with are, as at least some of their opponents claim, paternalistic.

The paper proceeds in three stages. In the next section I will start by explaining the key features that appear in accounts of what paternalism is, and then explain the problem that apparently paternalistic public health policies raise for those accounts. The paper then considers two ways in which one might try to respond to this problem. One possible response, to be considered in section two, is to rethink what the aim of these public health policies is. I will argue that this will only work for some cases and so an alternative is needed. This response, the focus of section three, argues that in order to accommodate the claim that things like mandatory seatbelt policies are paternalistic we need to allow that the target of a paternalistic action or policy can be a group not just an individual. Because many standard accounts of what paternalism is do not accommodate this, I will argue that such accounts need to be modified. Furthermore, making this change requires us to take the target of the interference or imposition that paternalistic 
policies involve to be the group rather than the individual. This change, or so I will argue, has important implications for questions about the normative significance of paternalism.

\section{The problem}

There are a number of different accounts of what paternalism is in the literature. Whilst there are important differences between these accounts, in general they take there to be two (or in some cases three) features that are necessary for something to be a case of paternalism. In this section I will start by saying a bit about each of these, before going on to explain how accounts with these features struggle to explain why some apparently uncontroversial paternalistic actions (such as making the wearing of seat belts mandatory) are paternalistic.

The first feature that an act has to have for it to count as paternalistic is that it is done with the aim of benefitting (where 'benefit' should be taken to include preventing harm) the person on whom it is imposed. ${ }^{2}$ Actions done with that aim may not in fact do so, and actions that do provide a benefit need not have been undertaken with the aim of providing that benefit. For example, banning smoking in public places has in many cases been argued for on the basis that it is needed to protect other people from being harmed by smokers. Smokers may benefit but this is not generally thought to be enough to make it paternalistic - in contrast to the case where the same policy is introduced with the aim of benefiting smokers. Examples like this would create problems were we to characterize paternalism in such a way that for something to be paternalistic it 
must actually benefit another person, rather than aim at benefiting them. For this reason I will not be considering such accounts here.

Not all cases in which one person aims to benefit another are paternalistic - for example, a surgeon who carries out an operation with the valid consent of her patient aims to benefit that patient but would not be thought to be acting paternalistically when she does so. As such, it is generally held that another feature (or features) is needed if an act is to be paternalistic. This can be spelt out in a variety of different ways. For example, Gerald Dworkin takes it that the paternalist interferes with the other person without their consent (Dworkin, 2010), James Childress takes it that in acting the paternalist does not acquiesce in the preferences, choices, or actions of the other person (Childress, 2007, p.223), David Archard takes it that the paternalist usurps the choice made by the other person (Archard, 1990, p.36) and Ronald Dworkin takes it that the paternalist imposes a decision on the other person contrary to that person's own sense of what is good for them (Dworkin, 2011, pp.361-2). As it is not this feature (or features) of the accounts I am considering that will be called into question in what follows I will for the most part simply refer to this as a requirement that for an act to be paternalistic it must in some sense impose a change on the other person. ${ }^{3}$

If this is what paternalism is then it is not hard to see why it is thought to be pro tanto wrong. Paternalism denies those affected by it the chance to make their own decisions about what is important to them and how to live their life, and as such fails to accord them the respect they are owed. This point has sometimes 
been made in terms of a person's desires about how their life should go - Gerald Dworkin, for example, expresses this when he writes, "We desire to be recognized by others as the kind of creature capable of determining our own destiny. Our own sense of self-respect is tied to the respect of others ..." (Dworkin, 1988, p.112; see also Berlin, 1969, p.131). Alternatively it can be made in terms of our interest in being treated as someone to whom these things are important (Dworkin, 1988, pp.108-113; Owens, 2012, pp.167-168, Hausman, 2012, p.90). To fail to do this is both to fail to recognize that we are autonomous and to treat us as though we are not an equal moral agent (see Dworkin, 1988, p.110). If this is right, then it seems that there are moral reasons not to introduce paternalistic public health policies. What makes those policies paternalistic would also make them pro tanto wrong.

Whilst at first sight it might appear that policies like mandatory seatbelt policies meet these requirements, closer examination will show that they do not. The benefit from wearing a seatbelt is that it protects you against being seriously injured or killed in a crash. But not everyone who wears a seatbelt will benefit in this way. There will be some people who wear a seatbelt but are never involved in a crash or any other incident in which their seatbelt protects them. On the other hand, there will be some people who, although they wear a seatbelt, are nevertheless killed or seriously injured in a crash. Their seatbelt in these cases did not protect them when they needed it. Because of this when introducing a mandatory seatbelt policy a policy maker will generally not be aiming to provide this benefit to everyone affected by the policy - where they know that acting in a 
certain way will not achieve some goal a policy maker cannot, on pain of severe irrationality, be aiming to achieve that goal when she acts in that way.

Recall, however, that to be paternalistic an action must be done with the aim of benefitting the person on whom it is imposed. It now seems that in the case of mandatory seatbelt policies this is not the case. The policy maker does not aim to benefit all those on whom she imposes the requirement to wear a seatbelt. Furthermore, it also turns out not to be the case that there is any individual of whom it is true that in introducing the policy the policy maker aims to benefit them. To see this suppose that the government's aim in introducing a mandatory seatbelt policy is to reduce the number of vehicle users who are killed or seriously injured. Now consider a randomly selected member of the population call him Bill. As it happens Bill gets killed in car crash whilst wearing his seatbelt, and so wearing the seatbelt does not benefit him. Does this in any way mean that the policy has not achieved its aim? The short answer is that it needn't. That is, the policy may well achieve its aim (which recall is to reduce the numbers killed, not to reduce them to zero - something that such a policy cannot do) even though Bill does not benefit. But, if the policy can achieve its aim without it benefiting Bill, then benefitting Bill is not part of the aim of the policy. Recall, however, that Bill was any randomly picked member of the population. As such, what is true of him will be true of every other member of the population too.

Effectively it does not matter in terms of achieving the aim of things like mandatory seatbelt policies who benefits from them, as long as some people do. But this means that benefiting any particular individual is not part of the aim of 
the policy. The policy, we might say, aims at benefiting statistical individuals, not identifiable individuals. It would appear to follow from this that there is no one who is affected by the mandatory seatbelt policy of whom it is true that the policy aimed at benefiting them. But in that case it does not seem as if the policy treats anyone paternalistically. This creates a problem for the accounts of paternalism that I have been using here. A policy that introduces a requirement that vehicle users wear a seatbelt in order to reduce deaths and serious injuries among vehicle users looks to be paternalistic. But it now seems that on current accounts of what paternalism is this is not the case.

One possible response here would be simply to bite the bullet and accept that the kinds of policy I have been talking about are not paternalistic. This though has significant costs - the examples I have been using are fairly generally held to be uncontroversial cases of paternalism. An alternative is to argue that I am wrong to deny that everybody benefits from the introduction of a policy that requires people to wear seatbelts. I will consider this option in the next section. As we will see whilst this may cover some instances of the kind of policy I am concerned with here it cannot cover them all.

\section{Rethinking the Benefit}

In setting out the problem above I took it that the benefit of wearing a seatbelt is being protected from death or serious injury in a collision. But that isn't the only option - for example, it could be argued that the benefit of wearing a seatbelt is having a lower chance of being killed or seriously injured in a collision. Because this is a benefit received by everyone who wears a seatbelt as the result of a 
mandatory requirement to do so it might appear that we can avoid the problem set out above.

For this proposal to work it must be the case that having a lower chance of death or serious injury is a benefit. But some care is needed in spelling out the benefit here if this is to be the case. Consider a person who is killed whilst wearing his seatbelt (like Bill in the example above). If having a lower chance of death or serious injury in a car crash is a benefit, and wearing a seatbelt provides this benefit, then it must be the case that Bill benefits from wearing a seatbelt. But this sounds wrong. Bill's seatbelt does nothing to benefit him - he would have been no worse off had he not worn it.

However, in expressing the thought that Bill does not benefit from wearing a seatbelt we judged this from a position after the event (in this case Bill's crash) where we know what happened. In contrast, when we say that someone is better off having a lower chance of death or serious injury we are making that judgment before the event (in this case at the time Bill starts his journey). Before he sets out we do not know whether or not Bill will crash and if so whether his seatbelt will save him. But we do, it seems, know that his seatbelt may save him and that is enough to show that he will be better off (given what we know at that time) if he wears a seatbelt. That is, when determining what is better for someone in a case like this it is natural, as John Broome points out, to use the probabilities of different outcomes pertaining at the time of the decision (Broome, 1991, p.225). It is this that makes it seem plausible to say that having a lower chance of serious injury or death is a benefit. 
What is needed, then, in order to capture the idea that everyone benefits from wearing a seatbelt is a way of characterizing this benefit such that it is tied to the time of the action. One way to do that is to argue that the benefit to each individual affected by a mandatory seatbelt policy is that it brings it about that they do something that has a higher expected utility than they would have done in the absence of that policy - where the expected utility of an option is calculated by a cost-benefit analysis taking account of the probabilities of the different outcomes that could arise from taking that option. In this way it seems that we can avoid the worry that people like Bill in our example do not benefit from being required to wear a seatbelt. Requiring Bill to wear a seatbelt does bring it about that he does something that has a higher expected utility than would have been the case if he had not been required to do so (as then he would not have worn his seatbelt). ${ }^{4}$ It might appear that in this way we can get what we have been looking for - an account according to which everyone who wears a seatbelt as a result of the introduction of the mandatory seatbelt policy benefits from doing so.

This, however, would be to move too fast. Whilst in some cases, and the seatbelt example may be one of these, it may be that everyone (given their own values) would have a higher expected utility by acting in one way (driving with a seatbelt) than in another (driving without a seatbelt), in others things are far less clear-cut. Consider the case of making it mandatory to wear a helmet when riding a motorbike where this is done to benefit bike riders. Those who oppose policies of this type may argue that wearing a helmet would deprive them of 
things that are of value to them - such as the sense of freedom that comes with riding without a helmet. If they value these things highly enough then it could turn out that wearing a helmet when riding their motorbike would not have higher expected utility for them than riding without a helmet (see Coons and Weber, 2013, p.9). As such, they would not benefit from the introduction of a mandatory helmet policy in the sense of 'benefit' that is at stake here.

However, this may not matter for our purposes here. I have already argued that we should not take it that for an action to be paternalistic it must benefit its target, rather what matters is that the policy maker be aiming to benefit the target. If the policy maker judges that people will all have a higher expected utility if they wear a seatbelt when driving or a helmet when on a motorbike, then it may well be the case that in introducing a policy to make wearing a seatbelt or helmet compulsory she is aiming to benefit all of those whose behavior is changed by the policy on the account of 'benefit' outlined above. In that way it would appear that the policy does fit the first, benefit based, criterion for something to be paternalistic.

It also seems that such a policy will fit the second criterion for something to be paternalistic outlined above in at least some cases. As we have seen the policy maker on this account acts to bring it about that each individual does what she (the policy maker) judges to be good for him (in the sense of having a higher expected utility). Where this is done without the voluntary agreement of the person affected, it does appear that the policy maker interferes with the other person against that person's will and does so without his consent (as on Gerald 
Dworkin's account - Dworkin, 2010), and imposes a decision on them contrary to their own sense of what is good for them (as required on Ronald Dworkin's account - see Dworkin, 2011). Similarly in acting in this way she is not acquiescing with the actual preferences, choices and actions of the other person (as required on James Childress' account - see Childress, 2007).

That paternalistic policies have these features has been pointed out before. For example, N. Scott Arnold writes that, "Whatever their ultimate goals, the proximate goal of [paternalistic] laws and regulations is to get people to do what is in their best interests, as state officials see it." (Arnold, 2009, p.109) What is different is the way that I have spelt out what it means to talk about 'best interests' or 'benefits' in this context. This difference, however, means that the account developed here will not be able to explain why some policies that appear paternalistic are paternalistic. All that it shows is that if policy makers act with the aim of benefitting everyone on whom their policy is imposed (by bringing it about that people do what has a higher expected utility at the time they act), then that policy will be paternalistic. However, it is unlikely that this will cover all public health policies that appear intuitively to be paternalistic. This is because it relies on a particular account of what the policy maker's aims in introducing such policies are. More specifically it relies on the idea that in introducing public health policies policy makers' aims are to benefit individuals not populations. To explain why policies with the latter type of aim would be paternalistic a different approach is needed. It is to this that I want to turn in the next section.

\section{Moving Entirely to the Group Level}


The problem identified in this paper is that whilst on current accounts of paternalism an act is only paternalistic if it is done with the aim of benefitting the person on whom it is imposed, many public health policies are not introduced with the aim of benefiting any particular individual on whom they are imposed. At its heart this problem stems from the fact that, as Angus Dawson and Marcel Verweij put it, many public health policies "aim to realise health benefits at a group or population level." (Dawson and Verweij, 2007, p.7) If the aim is irreducibly to benefit the group (rather than the individuals in the group) then the only way for this to be paternalistic is if the imposition is also on the group (rather than on the individuals who make up the group). In this section I want to consider whether an account of this type can be made to work.

In everyday life we readily talk about things that benefit or harm groups of people (where these can be picked out in different ways). How we conceptualize this benefit may depend on how we conceptualize the relevant group - for example, whether we think of it as merely a group of people who share some feature (say that they ride motorbikes) or as a community which can thrive, or decline, in its own right. However we do this we may hold that collectively a group benefits if some members of that group live longer or avoid serious injury, or if the average utility of the group goes up, or if there is less inequality within the group. Indeed, if we are to hold that policies can aim at improving collective well-being, then something along these lines must be correct. As we have seen things like mandatory seatbelt policies need not aim to benefit everyone who is required to wear a seatbelt as the result of introducing that policy, and nor is it the case that there need be any individual of whom it is true that the policy aims 
to benefit that person. But such a policy nevertheless does seem to be aiming a providing a benefit, and the group is the only thing left that it could be aiming to benefit (for an account of different ways of thinking about collective benefits see Dawson, 2011, pp.14-17). In saying this it is important to note that it need not be the case that the group that the policy aims to benefit is a community (in any rich sense of community) or self-governing group. In the case of mandatory seatbelt policies the group that the policy aims to benefit are those who travel by vehicle.

Before continuing there are two possible objections that need to be considered at this point. The first is that talk of benefiting a group is merely metaphorical - it is only individuals who can benefit, and there is nothing over and above the individual that could benefit. ${ }^{5}$ This is not the place to enter the debate about whether groups can benefit. Instead I want simply to point out that those who hold this type of highly individualistic position - groups are nothing more that mere aggregations of individuals and only individuals can benefit or be harmed cannot hold that public health policies that aim at group level effects are wrong because they are paternalistic. This is because if they deny the possibility of a group benefiting then the arguments in the previous sections of this paper show that such policies - including policies like making it mandatory to wear a helmet when riding a motorbike - are not paternalistic. As we have seen such policies do not aim to benefit those identifiable individuals affected by them.

The second objection that might be raised is that this position will collapse into that which we considered in the last section. ${ }^{6}$ In this section I am taking it that the policy maker's aim in introducing a mandatory seat belt policy is to reduce 
the numbers of people who are killed or seriously injured in car crashes. The way it does this is by reducing the chance that those travelling by car are killed or seriously injured, and hence by increasing their expected utility. Because of this it may appear incoherent to aim at the former without aiming at the latter. There are two things to say in response to this. The first is that even if it were incoherent to aim at reducing the numbers killed or seriously injured within a group without also aiming to increase the expected utility of some members of that group, there is nothing incoherent about aiming to reduce the numbers killed or seriously injured within the group whilst not aiming to increase the expected utility of every member of the group. The policy maker might, for example, think that making it mandatory for all bike riders to wear helmets would lower the expected utility of some riders whilst increasing the expected utility of others - whilst not knowing which are which. Such a policy would still appear to be paternalistic if it were not agreed to by the riders. Second, even if it were the case that reducing the numbers killed or seriously injured and increasing the expected utility of every group member were the same thing, it would not follow that it was incoherent to introduce a policy with the aim of bringing about the former but not with the aim of bringing about the latter. This could be the case, for instance, if a policy maker did not know these were the same. In that case it might be true that in introducing a mandatory helmet policy a policy maker was aiming to reduce the numbers killed in road accidents, but not true that in introducing that policy she was aiming to increase the expected utility of all those affected by it. This is because 'aiming at' as it is being used in discussions of paternalism is an intensional context - what we are aiming at in acting in a particular way depends on our beliefs. It is for this reason that a 
person could act with the aim of benefitting Superman but not with the aim of benefitting Clark Kent - even though these are one and the same individual.

If a group can benefit from a particular policy it also seems that such a policy could be imposed on a group. However, it is important to recognize that imposing a policy on a group without the agreement of the group is not the same thing as imposing something on each individual member of that group without that person's agreement. Similarly, one can acquiesce with the preferences of a group without acquiescing with the preferences of each member of the group. To talk about the preferences of a group or the agreement of a group is to talk about something that is a feature of the group as a whole. A group, for example, can agree to something even if there are some members of the group who do not agree to it. The preferences of a group (as a group) may not align with the preferences of each member of the group.

An example may help to make this clearer. Suppose the authorities that run an ice hockey league introduce a requirement that all players wear helmets as a way to reduce injuries to the players. If they do this without the agreement of the players as a group then this looks to be paternalistic. However, if the policy is introduced with the agreement of the players as a body on the account given here this will not be paternalistic. In the first case the policy is imposed on the players and disregards (either because it does not bother to find out or because it overrides) their preferences. In the latter it is not imposed as it is done with the agreement of the players as a body, and takes account of their preferences (and hence does not disregard them). This is so even if, as may well be the case, 
not all players agree with the requirement to wear helmets and some would prefer not to wear them. Those players are not treated paternalistically as the policy is not aimed at benefiting them; it aims at benefiting the players as a group. And the players as a group have voluntarily agreed to the policy. ${ }^{7}$

What this example shows is that there can be acts or policies that (1) aim to benefit some group, and (2) do so by imposing a change on that group without their agreement, or otherwise by disregarding the preferences of the group. If we describe such acts or policies as paternalistic, then we can easily see why things like mandatory seatbelt and helmet policies are paternalistic. For example, taking this approach we can argue that a policy that makes it mandatory for motorbike riders to wear a helmet aims to benefit motorbike riders as a group. Such a policy will be paternalistic if it is imposed on the riders as a group. In that case the policy maker aims to bring it about that the group do what she thinks is best for them as a group, and takes it that she does not need to defer to their judgment as a group about this (and hence does not need either to find out what they think, nor to acquiesce with their choices where she does know this).

Such an account of paternalism is structurally similar to the accounts of paternalism with which we started. However, as noted in the introduction these accounts define what paternalism is in terms that mean it is only possible to treat a person or individual paternalistically. To accommodate paternalism aimed at benefiting a group such accounts would need to be altered. One way in which this could be done is to say that those accounts as they stand are accounts of what is sufficient, but not necessary, for something to be paternalistic, and 
then to supplement them with the account outlined here. An alternative would be to replace terms such as 'person' or 'individual' in the accounts as they stand with a broader term that covers both individuals (or persons) and groups. If we are to accommodate the idea that policies such as mandatory seatbelt policies are paternalistic then some such alteration to current accounts of paternalism will be needed.

This change, however, has important implications for the normative status of paternalism when directed at groups. When setting out what paternalism is above I argued that what made paternalism pro tanto wrong was one of the features that made it paternalistic. This was that when the paternalist acts to bring it about that the other person does what she (the paternalist) thinks is best for them she does so in a way that indicates that she believes that she does not need to defer to their judgment in this matter (and hence does not need either to find out what they think, nor to acquiesce with their choices where she does know this). In acting in this way I argued the paternalist fails to treat the other person as an equal moral agent, and fails to give adequate weight to their interest in being recognized as someone to whom it is important that they run their own life.

Whilst when it comes to groups I have argued that structurally similar features are what makes an act or policy paternalistic in this case it will not, in general, follow that such paternalism is pro tanto wrong. This is because with some exceptions the group as a group is neither a moral agent, nor does it have an interest in being recognized as a body for which it is important that it run its own 
affairs. Neither the group of motorbike riders nor the group of vehicle users, for example, is a body of this type. They do not collectively run their own affairs and it would not set back their interests (as a group) not to recognize their authority to do so - they have no such authority. Furthermore, these groups are not collective moral agents, and so are not wronged by a failure to treat them as moral agents. That is, what made paternalism pro tanto wrong in the case where the target was a competent individual does not in general make it pro tanto wrong in cases where the target is a group.

This may become clearer when we consider the exceptions to this general point. There are some groups that are self-governing and for which it is important that they as a group are allowed to run their own affairs, and others that would be wronged by having a policy imposed on them because someone else thinks that they as a group would be better off if it was (for example, where the group is a minority ethnic group and the activity is something central to their culture). In these cases what makes an action paternalistic when directed at the group would be pro tanto wrong for the same reasons that it would be pro tanto wrong when directed at a competent individual. But as we have seen many groups, including the ones that have been my focus in this paper, are not like this. In saying this I am not saying that paternalistic acts or policies aimed at these groups is always morally permissible. A policy that requires riders to wear a helmet interferes with the rider's freedom and may be wrong on those grounds (I make no claim about this either way). My claim is simply that if this is wrong what makes it wrong is not what makes it a case of paternalism. As such, whilst in these kinds 
of cases whether a policy is justified requires careful argument, whether it is paternalistic or not does not have any place in such an argument.

\section{Conclusion}

In this paper I have taken it that public health policies such as making it mandatory to wear a seatbelt, or a helmet, where this is done to reduce the numbers of car or motorbike users who are killed or seriously injured in crashes can reasonably be taken to be paternalistic. My argument has been that current accounts of paternalism do not support such a claim. Such policies do not aim to benefit all of those on whom they are imposed, and there is no individual of whom it is true that in requiring that individual to wear a helmet or seatbelt the policy maker aims at benefiting him. As such, it is not the case that there is any person who is required to act differently as the result of introducing these types of policy where this requirement is introduced as a way of benefiting them.

There are two ways in which one might seek to address this problem whilst holding onto the idea that policies of this type are paternalistic. The first is to recharacterise what benefit the policy aims to produce. As I argued in section two there may well be some situations in which this strategy will work - for example, where we take the benefit to be bringing it about that the person does something with a higher expected utility. However, it is implausible to think that this will cover all public health policies because it relies on a particular account of what the policy maker's aim is in introducing them: an account that may be false. If the policy maker simply aims at reducing the numbers of vehicle users who are killed or seriously injured, for example, an alternative approach is 
needed. This requires that, as I argued in section three, we take the paternalist to be aiming at benefiting the group as a group - which in turn requires us to rethink what it is to impose the policy on the group or to fail to acquiesce with their preferences. Furthermore, once we have done this we can see that the features that appear to make paternalism pro tanto wrong when the target of the paternalism is an individual, will not make it pro tanto wrong when the target is a group. As such, there appears little reason to think that what makes public health policies (such as making it mandatory to wear a seatbelt or a helmet) paternalistic, where they are paternalistic, gives us any moral reason not to introduce them.

\section{$\underline{\text { Notes }}$}

1. As with most recent discussions of paternalism my focus will be on cases involving competent adults. Paternalism towards children raises different issues. 2. This feature is sometimes described by saying that the paternalist's intention or motivation is to benefit the other person. In what follows 'aims' should be taken to include such accounts. Whilst this is a feature of the accounts I am considering here it is worth noting that not all accounts of paternalism include this requirement (see, for example, Shiffrin, 2000).

3. It needs to be noted here that not all accounts of paternalism include a requirement of this type (see, for example, Thaler and Sunstein, 2008, p.5; BenPorath, 2010, p.23).

4. In arguing that Bill benefits in this way from the requirement to wear a seatbelt being imposed on him I am taking it that people do not always do what would be best for them even using their own assessment of what is best for 
them. There is considerable experimental evidence to support this position (see papers in Kahneman and Tversky, 2000; and Gilovich, Griffin and Kahneman, 2002).

5. I would like to thank Peter Schaber for pressing me on this point.

6. I would like to thank an anonymous referee for this journal for pressing me on this point.

7. My position here might be thought to be very similar to that of Joel Feinberg. Feinberg writes, "When most of the people subject to a coercive rule approve of the rule, and it is legislated ... for their sakes, and not for the purpose of imposing safety or prudence on the unwilling minority ("against their will"), then the rationale of the rule is not paternalistic." (Feinberg, 1986, p.20) However, on Feinberg's account in this case the policy is not paternalistic because it does not aim to benefit those who do not approve of it, whereas on mine it is not paternalistic because it aims to benefit the group (not merely those who agree with it) and does so with their agreement as a group.

\section{$\underline{\text { References }}$}

Archard, D. (1990). 'Paternalism Defined', Analysis, 50(1): 36-42

Arnold, N. Scott (2009). Imposing Values. Oxford: Oxford University Press

Beauchamp, Tom L. and Childress, James F. (2009). Principles of Biomedical Ethics $6^{\text {th }}$ Edition. Oxford: Oxford University Press

Ben-Porath, Sigal R. (2010). Tough Choices. Princeton NJ: Princeton University Press 
Berlin, Isaiah (1969). 'Two Concepts of Liberty' in I. Berlin (ed.), Four Essays on Liberty. Oxford: Oxford University Press, pp.118-172

Broome, John (1991). Weighing Goods. Oxford: Blackwell Publishers Ltd

Childress, James F. (2007). 'Paternalism in Health Care and Health Policy' in R.E. Ashcroft, A. Dawson, H. Draper and J.R. McMillan (eds.) Principles of Health Care Ethics $2^{\text {nd }}$ Edition. Chichester: John Wiley and Sons Ltd, pp.223-229

Coons, Christian and Weber, Michael (2013). 'Introduction: Paternalism - Issues and Trends' in Christian Coons and Michael Weber (eds.) Paternalism: Theory and Practice. Cambridge: Cambridge University Press, pp.1-24

Dawson, Angus (2011). 'Resetting the Parameters' in Angus Dawson (ed.) Public Health Ethics. Cambridge: Cambridge University Press, pp.1-19

Dawson, Angus and Verweij, Marcel (2007). 'Introduction: Ethics, Prevention, and Public Health' in Angus Dawson and Marcel Verweij (eds) Ethics, Prevention, and Public Health. Oxford: Oxford University Press, pp.1-12

Dworkin, Gerald (1988). The Theory and Practice of Autonomy. Cambridge: Cambridge University Press

Dworkin, Gerald (2010) 'Paternalism', Stanford Encyclopedia of Philosophy, http://plato.stanford.edu/entries/paternalism/ last accessed 14 May 2013

Dworkin, Gerald (2013). 'Defining Paternalism' in Christian Coons and Michael Weber (eds.) Paternalism: Theory and Practice. Cambridge: Cambridge University Press, pp.25-38 
Dworkin, Ronald (2011). Justice for Hedgehogs. London: Harvard University Press

Feinberg, Joel (1986). The Moral Limits of the Criminal Law: Harm to Self. Oxford: Oxford University Press

Gilovich, Thomas, Griffin, Dale and Kahneman, Daniel (eds.) (2002). Heuristics and Biases: The Psychology of Intuitive Judgment. New York: Cambridge University Press

Hausman, Daniel M. (2012). Preference, Value, Choice, and Welfare. Cambridge: Cambridge University Press

Kahneman, Daniel and Tversky, Amos (eds.) (2000). Choices, Values, and Frames. New York: Cambridge University Press

Owens, David (2012). Shaping the Normative Landscape. Oxford: Oxford University Press

Shiffrin, Seana Valentine (2000). 'Paternalism, Unconscionability Doctrine and Accommodation', Philosophy and Public Affairs, 9(3): 205-250

Thaler, Richard H. and Sunstein, Cass R. (2008). Nudge. London: Yale University Press

Wilson, James (2011), 'Why It's Time to Stop Worrying About Paternalism in Health Policy', Public Health Ethics, 4(3): 269-279 